\section{Autoantikörper gegen Granulozytenmembran}

\section{W. Stöcker}

Euroimmun Medizinische Labordiagnostika AG, Lübeck, Deutschland

Synonym(e) Anti-Granulozytenmembran-Antigen; GMA; Anti-GMA

Englischer Begriff granulocyte antibodies; anti-human neutrophil alloantigens

Definition Antikörper gegen Proteine der Membran von Granulozyten. Nicht zu verwechseln mit ANCA ( $\triangleright$ Autoantikörper gegen Granulozytenzytoplasma).

Pathophysiologie GMA gehören zu den Blutgruppenantigenen und werden kodominant vererbt. Im Wesentlichen werden 5 Antigensysteme (HNA1-5) unterschieden, von denen jeweils 1-3 verschiedene Ausprägungen bekannt sind. Ein Teil der Antigene ist auf dem Fc-Rezeptor der Granulozyten lokalisiert.

Klinisch sind GMA-Inkompatibilitäten hauptsächlich bei der neonatalen Immungranulozytopenie von Bedeutung, in diesem Fall werden die Antikörper von der Mutter diaplazentar übertragen. Weiterhin sind sie verantwortlich für schwere pulmonale Transfusionsreaktionen (TRALI-Syndrom, „transfusion associated lung injury“). Dabei aktivieren GMA eines Blutspenders alveoläre Granulozyten des Patienten und verursachen ein Lungenödem.

\section{Untersuchungsmaterial Serum.}

Analytik GIFT (Granulozyten-Immunfluoreszenztest) mit Granulozytenausstrichen oder im Flow-Zytometer: Suchtest.

MAIGA-(,,monoclonal antibody immobilisation of granulocyte antigens"-)Test: Antigen-spezifischer Test bei positiven GIFT-Resultaten.

Referenzbereich Negativ.

Diagnostische Wertigkeit Positive Testergebnisse in Verbindung mit der entsprechenden Klinik sind wegweisend für die Diagnose. Negative Ergebnisse schließen insbesondere das Vorliegen eines TRALI-Syndroms nicht aus!

\section{Literatur}

Stroncek D (2002) Neutrophil alloantigens. Transfus Med Rev 16:67-75 